confinements and she had post-partum hæmorrhage every time. It was on account of flooding after the seventh labour that Dr. Fraser was first called in by a midwife in attendance. At the time the patient was seen by me in consultation with Dr. Fraser the cervix was found to be so badly lacerated that it simulated malignant disease. The uterus was acutely flexed backwards. Ventrifixation was considered to be the best treatment. Patient at interview (June, 1908) said that her three confinements since the operation have been much "better." No hamorrhage after labour. No discomfort during pregnancy. The uterus was found to be in normal position; not the slightest tendency to backward displacement. (This is Case 2 in illustration of the article on "Hypertrophy and Erosion ...... a Pathognomonic Sign "already referred to.)

CASE 7.-Mrs. W. L., aged 27 years; not been pregnant. Patient of Dr. A. Carmichael, Barrow-in-Furness. Retroflexion with symptoms ; dysmenorrhoea worse since marriage. Examined under anæsthesia on May 11th, 1905. Uterus in acute retroflexion; bocy so large that it could not be manipulated forward without violence; not fixed by adhesion. Hysteropexis on May 13th, 1905. No divergence from the routine. Post-operative history without incident. Patient went home on June 21st. When pregnancy occurred in 1906 there were none of the usual symptoms, except amenorrhoea, and it was only the increasing volume of the uterus that settled the diagnosis. Labour began on Oct. 17th, 1906. It was rather slow at first and under anæsthesi occipito-posterior position was made out and rectified by manipulation. Forceps were then applied and labour completed without any incident worth noting. The puerperium was absolutely normal. The child was kept at the breast for some months, then the milk became scanty without apparent cause, except the maternal constitution.

These illustrative cases might be multiplied at intolerable length, but the present purpose can be served by the select few. The cases here given illustrate some of the chief points in the clinical history of pregnancy after hysteropexis. They are not chosen as the most favourable, but as characteristic some of them with even slightly unfavourable features.

The operation could not be pushed even though any one was foolish enough to try; it must be judged on its merits fairly stated, and proved by experience. I believe it will stand the test.

Manchester.

\section{CANCER OF THE COLON: A STUDY OF 72 CASES.}

BY H. S. CLOGG, M.S. LOND., F.R.C.S. ENG.,

ASSISTANI SURGEON TO CHARING CROSS HOSPITAL; SENIOR SURGEON TO THE EVELINA HOSPITAL FOR SICK CHILDREN, LONDON.

THE portion of bowel under consideration is that which reaches from the ileo-creal valve to the termination of the pelvic colon, that is about the level of the third piece of the sacrum. Cancer may occur anywhere in the colon, but it has a special selection for certain sites. It is convenient for the purposes of classification and treatment of cancer of the colon to divide the latter into its several arterial segments, by which I mean that the colon may be more or less divided into several portions by the vessels which supply it. Commencing at the cæcum these vessels are-the ileo-colic, the right colic, the middle colic, and the inferior mesenteric arteries. The ileo-colic and right colic arteries supply the cæcum and greater part of the ascending colon. It is better to consider this tract of bowel as one for the present purpose. The middle colic by its two main branches supplies the transverse colon and the termination of the ascending and commencement of the descending colons. The inferior mesenteric artery supplies the remainder. In this series of 72 cases the growths were distributed as follows :-

1. Those in connexion wath the ileo-colic and right coiio arteries. -17 were in this region. This site is conveniently called the cæcal region. The actual anatomical position of the growth is variable. In 16 of the cases the growth was examined either post mortem or as removed at operation. In only two was the cæcum entirely free from growth. The growth in these was in the ascending colon a little way above the site of the ileo-cæcal valve. In the remaining cases the cæcum was in whole or in part involved, often together with the ascending colon. Although all growths here are not strictly limited to the cæcum (on the contrary, a growth in the ascending colon may not-invade the cæcum at all) I consider it better to include them under one heading since I believe that the lymphatic drain is very much the same, and hence from an operative point of view they are inseparable, and I think clinically they will generally not be distinguishable.

2. Those in connexion with the middle oolic artery.-There were 18 in all situated in the bowel supplied by this artery. They were distributed as follows: (a) at the hepatic flexure there were five. These were more or less accurately at the exure, but involved the colon on either side of the flexure lso to some extent. (b) In the transverse colon without involvement of either flexure there were three. (c) In the region of the splenic flexure there were ten. The growth was not always strictly at the flexure, for in two cases it was at the commencement of the descending colon about two inches or so below the flexure. Such growths are in whole or in great part supplied by the middle colic artery and hence are cluded here.

3. Those in connexion with the inferior mesenteric artery.There were 37 situated in the iliac and pelvic colons. The distinction of this part of the bowel into the iliac and pelvic colons is in accordance with anatomical description and founded upon the more common arrangement of the peritoneum. But the latter is very uncertain and for the present purpose it has no particular bearing and the bowel is best considered as one and called the pelvic colon. The only feature of importance which can be assigned to the division is that a growth occurring in the bowel which is fixed to the iliac fascia is more likely itself to become adherent than one in the bowel which is suspended by a mesentery.

The importance of determining which arterial segment bears the cancer is, I think, very prominently brought out in the study of the lymphatic drain of various parts of the colon. It seems to me of great importance to bear this in mind when operating for these growths. Any operation for cancer is not merely that of removal of the primary growth but also its lymphatic drain as thoroughly as can be per formed in accordance with the anatomy of the part.

In the results which $I$ am about to report it may be understood that all cases which were examined post mortem or specimens which were removed at operation were submitted to microscopic examination. Several sections of each gland were examined, but not serial sections.

Cancer of the Colon in many Cases a Local Disease.

Forty-one cases I have traced to the post-mortem room The duration of symptoms in these ranged from a week to three years. In only six were there any visceral deposits, that is, in just under 15 per cent. It may be pointed out that it was not in those which suffered from a long duration of symptoms that the visceral deposits occurred; on the contrary, however, for the duration of symptoms was com paratively short, varying from two to six months. In 20 further cases I have been able to trace the after history. Some of these were successful excisions, others were those upon whom colostomy had been performed. The latter were not microscoped, and hence the diagnosis must remain in doubt. But it is probable that most, if not all, were cancer. seeing that there are not many conditions which may be confused with cancer of the large intestine. Many of these cases I have seen personally; in others I am indebted to the medical practitioner in attendance for very kindly furnishing me with the notes. In only one was there evidence of secondary visceral deposit. In one other upon which an anastomosis had been performed the whole abdomen filled with growth before death, and it was impossible to say where it was. These clinical observations are obviously unsatisfactory, but they may at the least be regarde as suggestive and bearing out the post-mortem patho logy. In the cases in which there were secondary visceral deposits post mortem the liver was involved in every one. In two in addition the ovaries were involved, in one case both ovaries, and in the second only one. In neither of these two was there any peritoneal deposit. Cancer of the ovary secondary to bowel cancer is well recognised and there are several papers upon the subject in the literature. The primary growth was in one at the commencement of the descending colon and in the other in the pelvic colon. In a further case the peritoneum was diffusely studded with tiny secondary growths, in addition to the infection of the liver. It may be gathered from these figures that cancer of the colon is in many cases a local disease and that secondary visceral deposits are not the great barrier to any radical operation.

\section{The Lymphatic Spread.}

In a communication to the Practitioner in 1903 I published some observations on cancer of the colon with especial reference to its lymphatic spread. Since that date I have had opportunities of extending those observations upon many more cases working on the same lines. The lymphatic drain 
of / the creum and appendix was the subject of one of the Arris and Gale lectures delivered at the Royal College of Surgeons of England in 1907. This lecture was founded upon the results of injection. I venture to think that the study of post-mortem pathology is equally useful and have confined myattention to that.

\section{The Lymphatics Involved in Gronths in the Caoal Region.}

This includes the growths which have also invaded the ascending colon or which are entirely in the latter portion of bowel at its commencement. There were 17 cases in all, of which 16 could be examined, 14 post mortem and two by the inspection of the specimens removed at operation. The situation of the glands was more or less constant. In only three-quarters of the cases were the enlarged glands infected. The glands were situated as follows. 1. In the ileo-colic angle there were always some found. The exact situation of these with relation to the bowel varied. Mostly they were more or less in close contact with the bowel, but at times they were at a little distance. 2. Continuous with (1) was a chain along the inner side of, and in close contact with, the ascending colon. The number of these and the height to which they ascended on the colon varied. In general they were only found on that part of the colon immediately above the ileocæcal valve. In a quarter of the cases these glands were not observed. In one case after excision of the growth I found some of this chain of glands left from a too low division of the colon. 3 . Continuous with (1) were a few small glands on the upper border of the ileum. These varied in numbers. Generally only one or two were found. In one case a chain extended for five inches along the small intestine. 4. In two cases there were two or three glands found more posteriorly - that is behind the growth. In three the ileo-colic glands extended nearly to the bifurcation of the ileo-colic artery. In a further ease of a very extensive growth, which had spread widely in the retroperitoneal tissues and the peritoneum, glands were found around the head of the pancreas. How the spread had taken place it was impossible to say, since the growth was very extensive and other glands, if any had been involved, had been swallowed up in the primary growth. In only this latter case could glandular involvement be said to be a factor prohibiting the radical operation. It was not, however, the only factor.

The operation for a growth in the cxcal region should be one which aims at the removal of the cæcum, ascending colon nearly to the hepatic flexure (this is necessary since the right colic artery must be sacrificed not because I have found any glands along the trunk of the vessel, but it often comes off in common with the ileo-colic, or, if not, at its eommencement it lies very near to the latter, and if a free excision of the tissue around the ileo-colic is done the right colic cannot be spared), the retroperitoneal tissues and the leaf of peritoneum covering the two named vessels, the lower six inches or so of the ileum, and the termination of the mesentery corresponding to the ileal branch of the ileo-colic artery. This can be attained in the following manner. The abdominal wall is incised in the right semilunar line. The peritoneum is divided on the outer side of the cæcum and ascending colon. With two fingers in the hole so made used as a director the peritoneum can be divided up as high as the kidney. Caution must be exercised then because of the duodenum. When the latter is identified the peritoneum may be further divided and the colon separated from the kidney and duodenum. The cæcum, ascending colon, and some retroperitoneal tissue are then stripped up from the posterior abdominal wall towards the mid-line. The ureter and spermatic vessels are exposed and preserved. The lower ileum, cæcum; ascending colon, some retroperitoneal tissue, and a leaf of peritoneum can then be drawn out of the abdominal cavity. Removal is best commenced from above. The colon is cut somewhere about the level of the hepatic flexure. In a moderately spare subject the vessels can be recognised behind the leaf of peritoneum. These are the right colic and the ileo-colic arteries. They as often as not come from a common trunk. If they can be recognised so much the better. If not, by dividing along the line of uplifted peritoneum from above down, the first large vessel will be the right colic artery. The ileo-colic artery is then ligatured. The commun trunk of these two vessels may only be encountered. This depends upon how far it has been possible to raise the peritoneum from the posterior abdominal wall and also upon the anatomical arrangement of the vessels. When the common trunk or the separate branches have been divided the section is carried down to the lower ileum so as to remove about the last six inches or so of it. Particular attention must be paid to the last intestinal branch of the superior mesenteric artery, and it should not be injured unless a corresponding length of small gut be removed. It is advisable to see this branch if possible and to plan the cut in the mesentery so that the ileum will be sectioned at the junction of the anastomosis of the ileo. colic and superior mesenteric arteries. In one case after removal of a cæcal growth there was gangrene of some length of small bowel. It will be easier to avoid cutting the intestinal branches of the superior mesenteric artery, I believe, if the section be commenced from above and the mesentery and lower ileum be left to the last. For by working in this way as more and more of the colon is freed it can be carried outside of the line of the direct field of operation, and by drawing upon it the lower mesentery can be stretched and a good view obtained of the anastomosis probably. There may be some glands behind the cæcum, but they are closely in contact with the latter and will readily strip off the iliac fossa. The end of the divided colon is closed and the ileum joined to the most accessible part of the transverse colon.

\section{The Lymphatic Drain of the Bonel supplied by the Middle Colic Artery.}

I confess my numbers here are far too small to be of any positive value and I only mention my results as being suggestive.

The hepatic flexure.-Five cases only in this series were at the hepatic flexure. Two of these were examined post mortem ; in both glands were present near to the growth and also in the mesocolon at a variable distance from the transverse colon and extending some little way from the primary growth. One further case was successfully excised but is too recent to be of any value. Glands were present in the vicinity of the growth. In two cases the growth was adherent posteriorly and anastomosis was the only possibility. Growths in the hepatic flexure would seem to be peculiarly bad from the surgical standpoint. The arrangement of the peritoneum here varies ; as often as not there is no mesentery to the colon which is in intimate contact with the duodenum and pancreas. No wonder is it that adhesions are early in these growths and that excision, as I judge from literature, has not been very often possible. The hepatic flexure is a more or less fixed part of the colon, but it can be readily made mobile. This is secured by a free division of the peritoneum on the outer side of the ascending colon and the serous membrane as it passes from the colon to the liver. If the gastro-colic omentum be also divided a considerable range of mobility is given to this part of the colon. This I should suggest as the plan of procedure in the removal of these growths. I suggest also that the corresponding half (or as much as can be) of the mesocolon requires removal in order to secure the lymphatics which pass here. The section of the bowel may be begun at the transverse colon and will be somewhere about the middle of the latter as the right branch of the artery will be cut. If the ascending colon has been freed by division of the peritoneum along the onter aspect it probably may be joined to the cut end of the transverse colon. In separating a growth from the pancreas and duodenum only a little of surrounding tissues can be removed. The amount will depend upon the extent and development of the mesentery in the region. By commencing the section at the transverse colon a clearer view of the parts will be given.

The transverse colon. - There were only three growths here. One was successfully excised. This was a large growth in the centre of the transverse colon. The glands in the immediate vicinity only were affected. Cancer cells were not found in the glands. Nearly three years later the patient developed intestinal obstruction and died. The obstruction was caused by adhesions. There was no evidence of any recurrence of the cancer. In a second case the growth was irremoveable. There were many enlarged glands in the mesocolon and in the great omentum. Lateral anastomosis was performed. One case was examined post mortem and here glands only close to the growth were enlarged. 
The splenic flexure rugion. - There were ten cases of cancer here. The growth was practically at the flexure in eight and in two was really at the commencement of the descending colon. Seven were examined post mortem, but in only six have I a note of the glands. In one the growth was of large proportions and adherent to neighbouring structures and no glands could be found. In the five cases glands were enlarged in the vicinity of the primary growth, in the angle of the flexure or a little posterior to it in relation to the spleen, or to the inner side of the descending colon. In one case glands were found in the adjacent great omentum. In three glands were also present in the mesocolon near to the lower border of the proximal transverse colon. In a further case which was successfully excised the patient is well six years after. In this there was a chain of glands running along the transverse colon and half of the latter was removed. In four out of the six cases the glands were infected with cancer. Glands per se would not have prevented a radical operation in any one of these cases.

I would suggest that the removal of a growth in the splenic flexure region be planned on the same lines as that for one of the hepatic flexure. The splenic flexure may be mobilised by division of the peritoneum on the outer side of the descending colon and the costo-colic ligament. I would also suggest that the corresponding half of the transverse colon also requires removal in order to remove the lymphatic drain which is in the mesocolon. I have not seen glands in association with the left colic artery but it seems probable that the lymphatics may pass this way. The descending colon, after division of the peritoneum on its outer border may be stripped inwards over the lower pole of the kidney and freely excised with the possible lymphatic drain along the left colic vessels.

\section{The Lymphatic Drain of the Ilio-pelvic Colon.}

The inferior mesenteric artery supplies this tract of bowel. Arising from the inferior mesenteric artery at about half to three-quarters of an inch from its commencement is the left colic artery. The latter runs upwards and to the left well over the iliac crest to the descending colon, anastomosing with the middle colic artery below the splenic flexure. The left colic artery may be said to supply that part of the colon from two inches or more below the splenic flexure to a point in the iliac fossa. The anastomosis between the left colic and the next vessel (the sigmoid artery) is a little below the level of the iliac crest. The sigmoid artery arises from the inferior mesenteric artery just below the left colic. It usually almost at once divides into two branches of nearly equal size. These vessels form arches which supply the loop of bowel from somewhere near the iliac crest to the lower end of the pelvic colon-that is, to about three inches or so above the peritoneal reflection at the base of the pelvis. The sigmoid vessels are for the most part between the layers of the mesentery of the pelvic colon but if the latter be absent in the iliac fossa for a short course the upper arteries may be retroperitoneal. The third vessel from the inferior mesenteric is the superior hæmorrhoidal artery. This passes over the pelvis in close contact with the brim and supplies the lower part of the pelvic colon.

Assuming that the glandular drain from the pelvic colon would more or less closely follow these vessels the first care is to determine from which arterial segment of bowel the cancer arises. This has been possible in many cases without any dissection. But in those cases where the mesentery is short the point may further be demonstrated after freeing the bowel by division of the peritoneum in the iliac fossa on its outer side and stripping it in towards the mid-line. The bowel is thus separated from the iliac fossa with the retroperitoneal tissue over the ureter and spermatic vessels to the origin of the inferior mesenteric trunk. By prolonging the incision in the peritoneum down along the pelvic wall, taking care to avoid the above-named structures, which have been already exposed and can therefore be readily protected, the whole ilio-pelvic colon may be separated from all its connexions, except the vascular supply and the leaf of peritoneum on the mid-line aspect. This enables the arteries to be freely exposed and it may be determined which vessel supplies the cancer-bearing portion of bowel.

Eighteen post-mortem examinations were made upon growths in the pelvic colon. In 16 of these the growth was in that part of the colon supplied by the sigmoid artery. In two it was quite low down and was supplied, anyhow in part. y the superior hæmorrhoidal artery. In no case was a growth situated in that part of the colon from two inches or so below the splenic flexure to the middle (about) of the iliac fossa. In some (two at least) of the growths in the splenic flexure region the left colic artery in part supplied it, or presumably it did as judged from its situation. I have not found any glands along this artery but then my chances have been too few to observe growths in this region, but nevertheless should consider that in such growths it would be advisable to remove the descending colon, the peritoneam, retroperitoneal tissues, and left colic artery. In 17 of the 18 cases enlarged glands were present. In every instance they were found in close proximity to the primary growth. In six glands were found at some distance from the primary growth near to, or at the base of, the mesentery. They were more or less in association with the vessels supplying the bowel. If the bowel were well freed as described above it was seen that the glands were not the retroperitoneal ones along the iliac vessels, but were actually situated between the layers of the mesentery. The extent of the glandular enlargement varied in these six cases, but in three it may be said that the highest gland was well below the origin of the sigmoid artery, whilst in three glands were higher than this and were more or less in connexion with the inferior mesenteric artery, and even higher than this, that is, they were the lumbar chain. Believing that the spread would tend to be finally along the inferior mesenteric artery I have always looked particularly for glands along the latter vessel, but bave only found them in the cases indicated. In many cancer was absent in the glands, and, in fact, in only twothirds of cases were cancer cells found. In addition to these post-mortem examinations there were eight cases of excision, with a very moderate resection of mesentery. In one a local and superficial glandular recurrence took place; this was excised and four years later there was no evidence of recurrence. A second recurred extensively in the lumbar glands. Five of the remaining six are in good health at intervals varying from ten months to three years. The sixth cannot be traced.

These figures incline one to the belief that cancer in this region is, for some time anyhow, a more or less local disease and involves those glands only in the immediate neighbourhood. It also shows that all enlarged glands are not necessarily cancerous, and it may be suggested that if the radical operation is thought impossible on account of glandular involvement only the operation need not be always at once renounced, but may be undertaken in the hopes that the level of an extensive resection will be above the most distal glandular cancer-infection. It may be mentioned here that in this series glandular involvement only was rot in any single instance a karrier to the radical operation. In three cases, it is true, glandular infection would have, $\mathbf{F}$ think, prevented removal, but in these there were other contra-indications, such as adhesion of the primary growth.

Although a very fair amount of success has in this series been attained by the removal of a very moderate amount of the lsmphatic tract it is not my intention to advocate such a limited resection. My observations lead ne to the belief that in cases where the cancer is in that rart of the bowel supplied by the sigmoid artery a resection of this loop with the contained mesentery to the origin of the vessel $w i l l$ be the most satisfactory method of dealing with it. It is quite easy to ligature the inferior mesenteric trunk nearly at its origin with the removal of the tissue around it, but in the cases I have examined with glands along this vessel this would not have been sufficient. It has always seemed to me that such a procedure would of necessity mean a colostomy, and having very serious doubts whether anything is gained by it $I$ think that a resection just kelow this and the avoidance of a colostomy would in the majority of cases be equally efficient.

The operation in brief is as follows. A long left paramedian incision gives the best access. The peritonerum is then divided in the iliac fossa to the outer side of the colcn; this division may extend up some distance along the de scending colon if necessary, and may be prolonged downwards into the pelvis. The colon and the retroperitoneal tissues are stripped up from the iliac fossa over the urcter and spermatic vessels which are scen and guarded, and it is necessary to expose these before tle incision is carried dcwn into the pelvis. This freeing of the colon may be carried 
on until the inferior mesenteric artery itself be seen. By spreading out the loop of bowel the individual branches of the artery may be seen unless there be an excess of fat. The intestine is then divided above and the incision in the mesentery is carried in to the trunk of the sigmoid artery, which is ligatured. The section may then be carried down the mesentery so planned as to avoid the superior hæmorrhoidal artery which will be found in close proximity to the pelvic brim, but with the intestine and mesentery on the stretch of course it may be a little displaced. The lower end of the colon is divided somewhere about the level of the pelvic brim. This will insure the intactness of the superior hæmorrhoidal artery and in addition will leave sufficient stump to enable an intra-abdominal anastomosis to be performed. If the separate vessels are not identified because of excessive fat then the operation may be conducted in precisely the same manner. The bowel may be divided at the upper end almost as high as the iliac crest without danger of the left colic artery. If the mesentery be divided now directly inwards towards the base of the sacrum the first large trunk will be the sigmoid artery. This vessel can thus be identified and the rest of the operation is as before If the growth be situated low down in the pelvic colon, that is in that part supplied by the superior hæmorrhoidal artery, then the latter must be sacrificed and also the retroperitoneal tissues in front of the sacrum. This operation cannot probably be completed intra-abdominally. It has always seemed to me a colostomy could not be avoided. But if this portion of bowel can be spared the upper end of the divided colon, which has been rendered mobile by the division of the peritoneum on its outer border, can be brought straight down to it.

Since preparing the above I have read a very interesting paper by Mr. B. G. A. Moynihan. This is in direct contradiction to my observations. Mr. Moynihan says that there is always a gland on the inferior mesenteric artery which must be removed. This gland would presumably lie about an inch or so higher than the line of section which I have indicated. Personally, I have not been able to find glands here except in the few instances mentioned already. It is what I should have expected to be the natural finding. But finding it so rarely, and believing that it was not the glands which formed the great contra-indication to the radical operation, and also thinking that ligature of the inferior mesenteric artery would entail a very extensive resection of the descending colon, I have advised the more restricted removal than that advocated by Mr. Moynihan. In the cases in which I have seen glands on the inferior mesenteric artery there has been more than one, and I have considered in such cases that all attempts at a radical operation would be out of the question. Mr. Moynihan considers that this gland which he describes and has found constant is the highest of the chain and must always be removed. I have always considered that ligature of the inferior mesenteric artery would necessitate excision of the greater part of the descending colon and that union of the two ends would be impracticable. But Mr. Moynihan has shown that this is not so. He says that the upper end of the sigmoid flexure is freely supplied with blood even after the inferior mesenteric trunk has been divided. Mr. Moynihan describes the operation he practises for cancer in this region, and I cannot do otherwise than cordially recommend anyone interested in the subject to read the paper where everything is most clearly stated. The paper is in Surgery, Gynceology, and Obstetrics for May, 1908.

\section{Clinioal Features.}

It is best to differentiate the growths in the cæcal region in considering the clinical characters, for they are not in all respects similar to those elsewhere.

The main clinical characters of growths in the cacal region.There were 11 males and six females. The youngest patient was 30 and the oldest 73 years. The ages ranged in decades were as follows :-

$$
\begin{aligned}
& \text { Between } 30 \text { and } 40 \text { years... }
\end{aligned}
$$

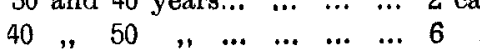

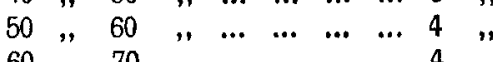

$$
\begin{aligned}
& \text { Over } 70 \text { years. } \\
& 1 \text { case. }
\end{aligned}
$$

In two cases there were apparently two separate abdominal growths. In one a small growth in the stomach and in the second an extensive one in the rectum were present in addition to that in the cæcal region. In the latter the abdominal symptoms were due to the rectal growth and it must remain unknown whether there were any which could be attributed to the cæcal one.

The most constant symptom is pain. This was in nine out of 15 cases of the nature of colic. In others it was a more or less persistent pain in the right iliac fossa without refer. ence to any intestinal disturbance. Apart from the colicky pains in the majority there was no other evidence of chronic intestinal obstruction. The bowels were not constipated neither were any coils in peristalsis seen, and it may be mentioned that post-mortem examination often did not show any hypertrophy of the small gut, as would be anticipated if obstruction had been present. Two, however, did suffer definitely from obstruction which ended subacutely, and a further case gave a history of having been obstructed for three days a short time before he came under observation. In the latter three the bowels were definitely constipated, but in the others there was little alteration from what may be considered normal to each of the individual patients. One patient passed a large quantity of tarry material at the beginning of his illness (six months before coming under observation). This was presumably blood. In no other instance was any blood noticed by the patient. On two occasions there was at times diarrhoea, the motions containing a little mucus. Loss of flesh was constant in all and it was often a very noticeable feature of the illness.

The presence of a swelling was very constant in creal carcinoma. The growths here are often of the large, bossy, and luxuriantly growing type and form masses of large dimensions. But in addition also the cæcum is quite super. ficial and easily palpable. In two a large abscess was present and a tumour could not be felt. In one (the case which exhibited a rectal growth) the tumour was verg small and not palpable. In one (an obese patient) a tumour was only felt under anæsthesia. In two cases chronic obstruction had ended subacutely and abdominal distension was marked when the patients first came under observation. In neither of these was a tumour palpable, but in all probability in a flat abdomen it would have been readily felt.

It must not be inferred that symptoms have been in existence for some time before a tumour may be detected clinically. In two the swelling was present practically from the time when the symptoms commenced. In two others it was known to be present very shortly after pain in the region was first experienced. In the remaining cases, judging from the size and easy palpation of the tumour, it conld have in all probability been detected at a much earlier period.

The main symptoms of a cæcal growth may be said to be pain, colicky or a persistent ache, generally absence of true obstruction, normal regularity of the bowels, and the presence of a tumour, associated with a progressive loss of flesh and deterioration of health. It may be noted that it is not uncommon to have a little fever. The thermometer may register $99^{\circ} \mathrm{F}$. or a little higher at times even in the absence of suppuration. This may be septic absorption or perhaps in some way due to the growth. This has occasionally been noted in uncomplicated growths elsewhere in the colon.

Three cases had the complication of suppuration around the growth. In one of these the onset was as a subacute appendicitis, but after draining the abscess for some weeks a firm swelling became palpable and later it fungated through the sinus. There were no symptoms of obstruction. In the second case there was a large abscess which had probably been present for some weeks. In the third case there was a very small collection of pus around the growth, not sufficient to cause adhesions which prevented removal. The similarity in such cases to appendicitis is marked, as it may be in uncomplicated cases of cæcal cancer.

Continued irritation as a possible etiological factor could not be asserted to be present in a single case. It may be thought that chronic constipation and an overloaded cæcum, stercoral ulceration, or a chronic appendicitis might have some influence, as irritation seems to play a part in some cases of cancer elsewhere. Chronic appendicitis seems not infrequently to have been present in many cases of carcinoma of the appendix. In not a single instance was it present in this series. Chronic constipation was nearly always absent. In only two cases have I noted it. Judging from the frequency which many writers of great experience regard cancer of the stomach to be preceded by a simple ulcer it might be thought that a similar condition would prevail in the rest 
of the alimentary canal. I have been particularly careful in my inquiries to ascertain the previous history, and in no case have I been able to suspect the sequence of simple inflammation and cancer in the intestine.

At the time when the patients came under observation it was only possible to excise the growth in five cases. Suppuration, adhesions to the posterior abdominal wall, to the anterior abdominal wall in one case and the small intestine were the reasons why extirpation could not be performed. I have traced two cases of excision. One was operated upon six years ago and is now in good health. In this the whole cæcum, ascending colon, and a part of the transverse colon with the lower ileum were removed. The second case, a less extensive resection of the colon, is well two years after.

Three cases of anastomosis I have been able to trace. Two died in five and seven months respectively. The third is alive but very weak nine months after the operation.

The clinical characters of gronths elsenhere than in the cacal region.-Age incidence. - The youngest was 15 and the oldest 89 years of age. Arranged in decades the numbers were as follows :-

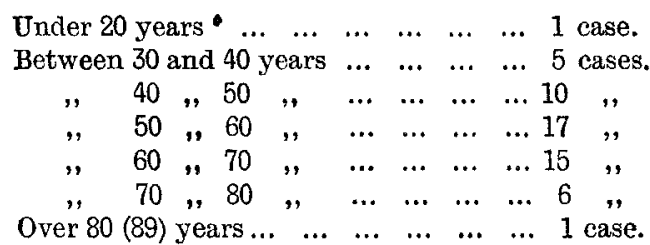

The sexes were about equally affected. There were 29 male and 26 female cases.

of the 55 cases, I have been able to learn the previous history of 46. In eight of them there was a history of longcontinued constipation. In three this had been present practically the whole lifetime. In the remainder it had been present for some years. But constipation was the only feature in these. It was never associated with any pain, diarrhea, or hæmorrhage, neither was there any symptom elicited suggestive of a simple stricture. In other words, I have not traced in any case the relationship between malig. nant disease and simple inflammation of the bowel.

The onset of symptoms could practically in all cases be dated with precision. It invariably affected persons in otherwise good health with the exception of those who suffered from chronic constipation, and this was not regarded as anything other than normal by these patients. In a few cases the onset was not quite so definitely fixed. The patients described their symptoms as of a few wreeks' or months' duration. But in by far the majority of cases the onset was more or less abrupt and its time of occurrence could be fixed with great precision. The symptoms of cancer are, of course, those which are directly dependent upon a progressive narrowing of the lumen of the bowel and the consequent hypertrophy of the gut above. Recurrent spasms of pain, gurgling of flatus as it is forced through the stricture, the discomfort caused by the inhibition of free passage of intestinal contents, anorexia, gradual failure of health and weight, and a progressive difficulty in the evacuation of the bowels are the main features. The hypertrophied gut aiove the stricture may be felt, or might be brought into prominence by a little gentle rubbing of the abdominal wall. This ought to be an early sign of a progressive stricture. Such symptoms were in general present in this series. They are all familiar and require no special comment. There are other clinical characters of which brief mention may be made. These are (1) the characters of the motions, and (2) the presence of an abdominal tumour.

1. There is constipation in the majority from the very commencement of the illness. But in a few this has not been so. In this series in about one-ninth this was said not to be present until some time after other symptoms. But in all it sooner or later was present. It may be that the bowels do not move daily or every other day, but what is of equal importance is that the quantity of fæces passed is distinctly less than normal. Attacks of diarrhoa sometimes occurred. Such were noted in about one-sixth of cases only, and in these the growth was in the pelvic colon with one exception, where it was at the splenic flexure. These attacks generally occur after a period of more than usually obstinate constipation. Some catarrh is no doubt set up by the retained and irritating intestinal contents. When the stricture relaxes and allows of a passage once more these catarrhal products are hurriedly rushed along and the result is that several loose motions may be passed for a day or so. Such motions may contain mucus and even blood. This was not a common symptom in this series. It is what is generally referred to as alternating constipation and diarrhoea. Constipation was the characteristic and diarrhoea the exception. When such spurious diarrhoa occurred it was unusual to have more than two or three attacks, and it would be very misleading to give as a, symptom of cancer of the colon alternating constipation and diarrhœa. Apart from this diarrhœa mucus was observed in the motions on five occasions. Four of these were growths in the pelvic colon and in one the growth was at the splenic flexure. Blood in the motions was absent in the majority of cases. By this is understood visible blood in no case was a microscopical or chemical examination made to determine its presence or absence. In one in the transverse colon, two at the splenic flexure, and in only 14 out of 37 growths in the pelvic colon was blood noted. In all it was particularly asked for and the stools were examined whenever possible.

2. A palpable tumour.-A tumour was by no means alway felt. Its presence will depend upon its situation, its size and the state of distension of the abdomen. When the abdomen was not too distended to permit of examination a tumour was felt in this series as follows. In two cases out of three at the hepatic flexure, every case (three) at the transverse colon, in three cases out of seven at the splenic flexure, and in seven cases out of 22 in the pelvic colon. In two additional growths in the latter region a mass of undetermined connexions was felt through the vagina. A tumour was palpable therefore in 15 cases out 35 in which the condition of the abdomen permitted of examination-that is, in about 43 per cent. of cases.

The duration of the symptoms of incomplete intestinal obstruction varied considerably before becoming complete. In one the earliest symptom was acute obstruction. No previous history of intestinal trouble could be elicited in this case. The patient was first seen when obstruction had been present for three days and the abdomen was generally distended without evidence of the site of obstruction. That the obstruction was chronic was easily seen from the hypertrophy of bowel. Compensation had been so well maintained that previous to the sudden obstruction there had been no trouble whatever. In two further cases the onset was ten and 12 days previously with an attack of subacute obstruction which yielded to simple measures. Obstinate constipation was present during the succeeding few days which culminated in complete obstruction. Obvious bowel hypertrophy of some duration was present in these cases. The duration of symptoms in the others was from two months to three years. About one-third during this period had suffered from one or more attacks of threatened obstruction which had yielded to aperients or enemata. It may be mentioned that in many (about two-fifths) the administration of frequent and strong aperients had probably actually produced the final obstruction. This may be considered as a warning.

In considering the causes of the terminal obstruction it may be said that there was not one case of volvulus of the bowel above nor one of intussusception, both of which are given as occurring sometimes. In one case the obstruction seemed to be enhanced by the kinking and adhesion of a lengthy loop of bowel above the growth. In two others it was probable that an abscess around the growth determined in part the obstruction. In no case could the impaction of a foreign body or fæcal accumulation be said to be the cause of obstruction.

The onset and progress of the terminal obstruction varied somewhat. In three acute dilatation of the cæcum was the earliest sign. So sudden was this and so pronounced was the distended cæcum that a volvulus or some other mechanical acute obstruction might have been suspected. All three cases gave a comparatively short history. In three in which the symptoms had been by no means urgent but merely those of chronic obstruction an acute dilatation of the colon occurred. The abdomen rapidly became swollen, vomiting was profuse and foul-smelling, and collapse was decidedly marked. Compensation in these had been maintained up to a certain point and then it would appear that the colon suddenly gave out. Possibly antiperistalsis may explain the cases of acute dilatation of the cæcum. In the majority the obstruction was more slowly progressive. The abdomen more slowly distended due to the more or less gradual distension 
of bowel farther and farther away from the site of obstruction. Well-marked peristalsis of small and large intestine was seen showing that whatever may have been the previous history the obstruction had been present for some time. The diagnosis of the site of the obstruction when the latter was complete with well-marked distension and peristalsis was in the absence of any palpable tumour impossible. A tumour in such cases was felt in five cases only.

Suppuration or perforative peritonitis occurred in 12 cases. In all except one the inflammation was in the peritoneal cavity. In this the growth was at the pelvic colon adherent in the iliac fossa. A large abscess was present in the iliac fossa behind the peritoneum and tracking upwards towards the lumbar region; this was traced directly to the growth. There are three ways in which the peritoneum may become infected :-

1. An ulcer in the caoum may perforate. There were five cases in this series. In three this occurred during the period of complete obstruction. In each the peritonitis was diffused. The growth was in the pelvic colon in two and at the splenic flexure in one of these. In the two cases, although chronic obstruction had been present for some time, it had not terminated acutely. These growths were in the pelvic colon. In both the cæcum was much distended, as shown at operation. In one, in addition, a perforation had occurred just above tho growth and the abscess had travelled up along the colon and formed a collection of pus under the left diaphragm around the spleen, with infection of the pleura.

2. In six cases the infection occurred through the base of the gronth. In three of these the peritonitis was diffused. In only one of these three did the perforation occur when the obstruction was complete. In three a ocalised abscess formed around the growth, slowly and nsidiously without any acute onset and not during the period of complete obstruction. In five the growth was in the pelvic colon and one at the splenic flexure.

3. In one case only did perforation of a stercoral ulcer above the growth occur and cause diffuse peritonitis. This occurred in the period of complete obstruction. The growth was in the pelvic colon.

In two cases there was an intestinal fistula. In both a growth in the pelvic colon had communicated with the bladder.

The occasions when it was feasible to perform a radical operation were comparatively few. In tabular form with contra-indications this is shown as follows :-

\begin{tabular}{|c|c|c|}
\hline- & Removal possible. & Removal impossible. \\
\hline $\begin{array}{l}\text { Hepatic } \\
\text { fexure. }\end{array}$ & $\begin{array}{l}2 \text { cases. } 1 \text { was } \\
\text { removed ; the } \\
\text { second complete } \\
\text { obstruction, un- } \\
\text { successful colo- } \\
\text { stomy. }\end{array}$ & 3 cases, adhesions posteriorly. \\
\hline $\begin{array}{l}\text { Transverse } \\
\text { colon. }\end{array}$ & $\begin{array}{l}2 \text { cases ; only } 1 \\
\text { operated upon. }\end{array}$ & I case, fixed posteriorly. \\
\hline $\begin{array}{l}\text { The splenic } \\
\text { flexure. }\end{array}$ & $\begin{array}{l}2 \text { cases, both re- } \\
\text { moved; } 1 \text { success- } \\
\text { ful ; } 1 \text { succumbed } \\
\text { from obstruction } \\
\text { due to adhesions. }\end{array}$ & $\begin{array}{l}8 \text { cases. I had secondary deposit } \\
\text { in liver, locally removeable; } 1 \\
\text { secondary ovary and adherent to } \\
\text { parietes; } 2 \text { diffusely adherent to } \\
\text { small intestine; } 2 \text { fixed to } \\
\text { parietes; } 1 \text { perforative peritonitis; } \\
1 \text { localised abscess. }\end{array}$ \\
\hline Pelvic colon. & $\begin{array}{l}13 \text { cases ; } 10 \text { ex- } \\
\text { cised : eight suc- } \\
\text { cessful, two } \\
\text { deaths. } 3 \text { com- } \\
\text { pletely ob- } \\
\text { structed, un- } \\
\text { successful colo- } \\
\text { stomy. }\end{array}$ & $\begin{array}{l}24 \text { cases. } 1 \text { case had diffusion of } \\
\text { growth over the peritoneum, ex- } \\
\text { tensive glands and secondary } \\
\text { liver; } 1 \text { secondary ovaries and } \\
\text { liver } ; 2 \text { adhesions and secondary } \\
\text { liver; } 6 \text { adherent to pelvic brim } \\
\text { or sacrum; } 4 \text { adherent to pelvis } \\
\text { and sullall gut; } 10 \text { cases compli- } \\
\text { cated by perforative peritonitis } \\
\text { or localised suppuration. }\end{array}$ \\
\hline
\end{tabular}

In only 19 out of 55 cases would it have been possible to remove the growth. Adhesions to surrounding structures were the great barrier. Secondary visceral deposits were once of themselves the only cause. Glands was a possible cause in one case of a growth in the transverse colon and in three of the growths of the pelvic colon would have prevented removal, but there were other contra-indications also present in these three cases. I have considered that in all cases where perforation or localised suppuration bas occurred remcval was contra-indicated. It is possible that if some of the cases of perforation of the crecum had been operated upon before the catastrophe removal might have been performed.

\section{Results of Operation.}

1. Exorsion.-One case of excision of the hepatic flexure is quite recent. One of resection of the transverse colon remained in perfect health for three years. He then developed acute obstruction from adhesions and died. There was not a trace of growth in the abdomen. One case of excision of the splenic flexure is well, six years after. Of eight resections of the pelvic colon only seven can be traced. One recurred in the glands and died nine months after the operation. A second recurred in the glands after the primary operation; these were excised and he was well four years afterwards. The remaining five are well at intervals of ten months, 14 months, 17 months, two years and ten months, and three years.

2. Anastomosis. -'Two cases of growths in the hepatic flexure lived four and 13 months respectively. One case of the transverse colon lived eight months. One case of the splenic flexure (this was associated with local suppuration) lived four months, and the second nine months.

Harley-street, W.

\section{Citinical athotes:}

\section{MEDICAL, SURGICAL, OBSTETRICAL, AND} THERAPEUTICAL.

\section{A NEW COMBINATION ELECTRIC WAVE APPARATUS AND ITS THERAPEUTIC VALUE.}

By W. Stansfield, M.R.C.S. ENG., L.R.O.P. LOND., LATE HOUSE SURGEON, MAYCHESTER ROYAL INFLRMARY; AND

\section{AlfREd Johnson, M.R.C.S. ENG., L.R.C.P. Lond.}

We have been impressed by the results obtained by the use of what we believe to be a new modification of the three-phase electrical current in the treatment of atony of muscular tissue, either striped or unstriped. The instrument which we have recently clinically tested is known as the Lloyd combination wave apparatus; it is simple and inexpensive. A four-volt accumulator drives a motor generator with three commutators producing three currents; there is a device of a shunt across the armature for the produetion of three minor currents. These three major and minor currents, all of sine nature, are led to three ordinary induction coils, from which wires are connected to three-pad electrodes. An electrical brake on the motor and a rheostat render the speed of the contractions well under control. In treatment of atony of the alimentary canal one pad is placed in the lumbar or sacral region and the remaining two on the abdominal wall. The three minor waves seem "to modify the effect of the three major waves as seen in the ordinary three-phase apparatus, and the effect is to produce a painless contraction of the muscles.

We have been using this apparatus for nearly a year and the following are notes of a few cases:-

CASE 1.-A. B., a slight pale lady with a congenitally small liver, never remembered having her bowels opened naturally, her motions always being of a very light colour. She was ordered an aperient strong enough to produce one motion a day and her diet was regulated. The throe eloctrodes were une mos described the apparatus sterted in a The three eloctro proced a mauner to produce slow contraction, and with the two front pads the 政 minu a a a time the required less aperients. Aperients were entirely stopped at the end of three
weeks, and the treatment was continued another week. Some three weeks, and the treatment was continued

CASE 2.-C. D., a little girl, aged eight years, pale, weak, and undersized, had not had her bowels opened without assistance since she was six months oll. She was treated only 21 times in two months, at the end of which she was taking very little medicine and often doing without, the electric treatment sufficing.

CASE 3.-F. F., a middle-aged lady, had suffered with constipation for two years, her abdomen being lax and flabby with a loaded colon She was treated daily for three weeks, also with gradually decreasing doses of aperients. She was entirely relieved at the end of this time her spirits and appetite better, her figure much improved, and she was stronger in every way.

CASE 4.-G. H. Was suffering from severe neuralgia of the fifth nerve. she had been under treatment for some time with the usual remedie and had received no benefit. We placed one pad on the abdomen and 